\title{
Hereditary Fibrinogen A $\alpha$-Chain Amyloidosis in Asia: Clinical and Molecular Characteristics
}

\author{
Masahide Yazaki ${ }^{1,2}, *$, Tsuneaki Yoshinaga ${ }^{3}$, Yoshiki Sekijima ${ }^{1,3}$, Fuyuki Kametani ${ }^{4}$ \\ and Nobuo Okumura ${ }^{2}$ \\ 1 Institute for Biomedical Sciences, Shinshu University, Matsumoto 390-8621, Japan; sekijima@shinshu-u.ac.jp \\ 2 Department of Clinical Laboratory Medicine, Shinshu University School of Health Sciences, \\ Matsumoto 390-8621, Japan; nobuoku@shinshu-u.ac.jp \\ 3 Department of Medicine (Neurology and Rheumatology), Shinshu University School of Medicine, \\ Matsumoto 390-8621, Japan; kiccho828@gmail.com \\ 4 Tokyo Metropolitan Institute of Medical Science, Tokyo 156-8506, Japan; kametani-fy@igakuken.or.jp \\ * Correspondence: mayazaki@shinshu-u.ac.jp; Tel.: +81-263-37-3427
}

Received: 26 December 2017; Accepted: 19 January 2018; Published: 22 January 2018

\begin{abstract}
Hereditary fibrinogen $\mathrm{A} \alpha$-chain amyloidosis ( $\mathrm{A} \alpha$-chain amyloidosis) is a type of autosomal dominant systemic amyloidosis caused by mutations in fibrinogen A $\alpha$-chain gene (FGA). Patients with $\mathrm{A} \alpha$-chain amyloidosis have been mainly reported in Western countries but have been rarely reported in Asia, with only five patients with A $\alpha$-chain amyloidosis being reported in Korea, China, and Japan. Clinically, the most prominent manifestation in Asian patients with A $\alpha$-chain amyloidosis is progressive nephropathy caused by excessive amyloid deposition in the glomeruli, which is similar to that observed in patients with $\mathrm{A} \alpha$-chain amyloidosis in Western countries. In molecular features in Asian $\mathrm{A} \alpha$-chain amyloidosis, the most common variant, E526V, was found in only one Chinese kindred, and other four kindred each had a different variant, which have not been identified in other countries. These variants are located in the C-terminal region (amino acid residues 517-555) of mature $\mathrm{A} \alpha$-chain, which was similar to that observed in patients with $\mathrm{A} \alpha$-chain amyloidosis in other countries. The precise number of Asian patients with $\mathrm{A} \alpha$-chain amyloidosis is unclear. However, patients with $\mathrm{A} \alpha$-chain amyloidosis do exist in Asian countries, and the majority of these patients may be diagnosed with other types of systemic amyloidosis.
\end{abstract}

Keywords: fibrinogen $\mathrm{A} \alpha$-chain amyloidosis; hereditary renal amyloidosis; Ostertag-type amyloidosis; laser microdissection; proteomics analysis

\section{Introduction}

Different types of hereditary systemic amyloidosis without peripheral neuropathy are often referred to as "Ostertag-type amyloidosis" in reference to Ostertag's description in 1950 of a German family in which several members died due to renal amyloidosis [1,2]. At present, hereditary non-neuropathic renal amyloidosis (also referred to as Ostertag-type amyloidosis) comprises a group of diseases associated with the variants of apolipoprotein AI [3], fibrinogen A $\alpha$-chain [4], lysozyme [5], apolipoprotein AII [6], apolipoprotein C2 [7], and apolipoprotein C3 [8].

Hereditary fibrinogen $\mathrm{A} \alpha$-chain amyloidosis (A $\alpha$-chain amyloidosis) is a systemic disease caused by the extracellular deposition of amyloid fibrils comprising fibrinogen $A \alpha$-chain variants induced by mutations in fibrinogen $A \alpha$-chain gene ( $F G A$ ) [4]. To date, 16 amyloidogenic $F G A$ mutations have been identified [4,9-16] (Table 1). The majority of patients with A $\alpha$-chain amyloidosis have been reported in European countries and the Unites States [2,17]. Although A $\alpha$-chain amyloidosis has also been reported in some Asian patients [12-14], it is still recognized as a rare disease in Asia. A $\alpha$-chain amyloidosis was not reported in Japan until we recently identified a sporadic case of a patient who 
was initially diagnosed with primary AL amyloidosis [14]. This indicates that some patients with A $\alpha$-chain amyloidosis who have not been correctly diagnosed may exist in Asia because of the low recognition of the disease and clinical similarity of this disease to other types of amyloidosis. Here, we describe the clinical and genetic features of $\mathrm{A} \alpha$-chain amyloidosis by paying special attention to Asian patients with A $\alpha$-chain amyloidosis, particularly the clinical and molecular characteristics of the first Japanese patient diagnosed with A $\alpha$-chain amyloidosis [14].

Table 1. Sixteen amyloidogenic FGA mutations.

\begin{tabular}{|c|c|c|c|c|}
\hline FGA Mutations & Protein Variants & Clinical Features & Geographic Origin/Ethnicity & References \\
\hline \multicolumn{5}{|l|}{ Missense Mutations } \\
\hline c. $1627 \mathrm{G}>\mathrm{A}$ & E524K & Nephropathy & Scottish & Rowczenio et al. [15] \\
\hline c. $1633 \mathrm{G}>\mathrm{A}$ & E526K & Nephropathy & Russian & Rowczenio et al. [15] \\
\hline c. $1634 \mathrm{~A}>\mathrm{T}$ & E526V & Nephropathy & US, Europe, Brazil, China & Uemichi et al. [9] \\
\hline c. $1670 \mathrm{C}>\mathrm{A}$ & $\mathrm{T} 538 \mathrm{~K}$ & Nephropathy & Chinese & Gillmore et al. [13] \\
\hline c. $1676 \mathrm{~A}>\mathrm{T}$ & E540V & Nephropathy & German & Gillmore et al. [13] \\
\hline c. $1712 \mathrm{C}>\mathrm{A}$ & $\mathrm{P} 552 \mathrm{H}$ & Nephropathy & Afro-Caribbean & Gillmore et al. [13] \\
\hline c. $1718 \mathrm{G}>\mathrm{T}$ & R554L & Nephropathy & Mexico, Europe, US (Afro-American) & Benson et al. [4] \\
\hline \multicolumn{5}{|l|}{ Deletion Mutations } \\
\hline c.1611delA (4886delA) & G519EfsX548 & Nephropathy & French & Rowczenio et al. [15] \\
\hline $\begin{array}{l}\text { c.1619_1622delTTGT } \\
\text { (4894_4897delTTGT) }\end{array}$ & F521SfsX547 & Nephropathy & North African & Rowczenio et al. [15] \\
\hline c.1620delT (4895delT) & F521LfsX548 & Nephropathy & French & Garnie et al. [16] \\
\hline c.1622delT (4897delT) & V522AfsX548 & Nephropathy & French & Hamidi et al. [11] \\
\hline $\begin{array}{l}\text { c.1624_1627delAGTG } \\
\text { (4899_4902delAGTG ) }\end{array}$ & S523RfsX547 & Nephropathy & Japanese & Yazaki et al. [14] \\
\hline c.1629delG (4904delG) & E524EfsX548 & Nephropathy & US & Uemichi et al. [10] \\
\hline c.1632delT (4907delT) & T525TfsX548 & Nephropathy & Chinese & Gillmore et al. [13] \\
\hline \multicolumn{5}{|l|}{ Insertion-Deletion } \\
\hline $\begin{array}{l}\text { c.1606_1620del, 1619_1620insCA } \\
\text { (4881_4895del, 4894_4895insCA) }\end{array}$ & $\begin{array}{c}\text { M517_F521del } \\
\text { insQSfsX548 }\end{array}$ & Nephropathy & Korean & Kang et al. [12] \\
\hline $\begin{array}{l}\text { c.1720_1721delGGinsTT } \\
\text { (5445_5446delGGinsTT) }\end{array}$ & G555F & Nephropathy & Norwegian & Rowczenio et al. [15] \\
\hline
\end{tabular}

Number of amino acids denotes the position in mature fibrinogen A $\alpha$-chain.

\section{Fibrinogen A $\alpha$-Chain Amyloidosis}

The first case of A $\alpha$-chain amyloidosis was described by Benson et al. [4] in 1993 in a PeruvianMexican population, segregating with a mutation in FGA as R554L. A $\alpha$-chain amyloidosis is characterized by excessive amyloid deposition preferentially in the renal glomeruli and clinically presents as proteinuria, hypertension, and azotemia [2]. Involvement of the liver and spleen may be observed in advanced cases of A $\alpha$-chain amyloidosis; however, excessive amyloid accumulation in the glomeruli is the most remarkable feature of this disease [2]. Moreover, amyloid deposits result in atherosclerosis or cardiomyopathy in some patients [17,18]. A previous study reported that clinical symptoms of $\mathrm{A} \alpha$-chain amyloidosis usually begin from the fourth to the ninth decade of life and that the median time from the progression of proteinuria to end-stage renal disease (ESRD) is 4.6 years [13]. However, some patients develop A $\alpha$-chain amyloidosis symptoms from the first or the second decade of life $[11,12]$. Most patients with $\mathrm{A} \alpha$-chain amyloidosis do not have any family history of renal disease or amyloidosis because of the variable penetrance of this disease [13]. Therefore, a sporadic case of A $\alpha$-chain amyloidosis may be frequently misdiagnosed as primary AL amyloidosis [19]. To date, 16 amyloidogenic FGA variants have been reported, of which seven are missense mutations and nine are deletion or insertion-deletion mutations (Table 1) [4,9-16]. Of the nine deletion or insertion-deletion mutations, eight result in an out-frameshift mutation. E526V is the most common variant detected in patients across the world $[2,9,13,17,20,21]$ (Table 1). Most patients with A $\alpha$-chain amyloidosis are heterozygous for the E526V variant; however, a recent study reported a Portuguese patient who was homozygous for the E526V variant [22]. While a genotype-phenotype correlation has not been investigated in detail, all described amyloidogenic mutations have been found to be associated with renal amyloidosis $[2,13]$. In addition, patients with A $\alpha$-chain amyloidosis having frameshift 
variants seem to show earlier disease onset (median age, 30 years) than those with single amino acid substitutions (median age, 59 years) [15].

\section{A $\alpha$-Chain Amyloidosis in Asia}

A $\alpha$-chain amyloidosis is the leading cause of hereditary non-neuropathic systemic amyloidosis in Western countries [17]. However, only a few cases of $A \alpha$-chain amyloidosis have been reported in Asia [12-14,23]. In 2005, Kang et al. [12] reported a sporadic case of a patient with A $\alpha$-chain amyloidosis in Korea who showed very early onset of the disease (at the age of 7 years) and rapid deterioration of renal function. The patient developed ESRD within 2 years after the disease onset. Renal biopsy showed severe glomerular enlargement with excessive amyloid deposits. Moreover, this patient had a unique frameshift mutation (c.1606_1620del,1619_1620insCA) in FGA, which was the first insertion-deletion mutation to be reported in patients with $\mathrm{A} \alpha$-chain amyloidosis. Later, Gillmore et al. [13] detected two novel variants, T538K and c.1632delT (a frameshift variant), in Chinese patients with A $\alpha$-chain amyloidosis. In contrast, Yao et al. [23] reported the case of a Chinese patient with $A \alpha$-chain amyloidosis who had the most common mutation, i.e., E526V, and who presented with proteinuria, hypertension, and renal failure.

\section{The First Case of A $\alpha$-Chain Amyloidosis in Japan: Clinical and Molecular Features}

In Japan, the vast majority (over $90 \%$ ) of patients with hereditary systemic amyloidosis are transthyretin-related familial amyloid polyneuropathy (hereditary ATTR amyloidosis). More than 300 patients are assumed to exist in Japan, and those patients usually present with severe peripheral and autonomic neuropathy, cardiomyopathy gastroenteropathy, and/or oculopathy. However, no patient with hereditary non-neuropathic renal amyloidosis (Ostertag-type amyloidosis) had been reported in Japan until we reported the sporadic case of a patient with $\mathrm{A} \alpha$-chain amyloidosis having a novel frameshift variant (4899_4902delAGTG) in 2015 [14]. This patient was a 40-year-old woman with rapidly deteriorating nephropathy [14]. The patient developed proteinuria at the age of 32 years, and renal biopsy showed excessive amyloid deposits in her glomeruli (Figure 1A,B). The patient did not have any overt signs of neuropathy, cardiomyopathy, oculopathy, or gastroenteropathy; however, gastroduodenal biopsy showed small amount of amyloid accumulation in the duodenal mucosa (Figure 1C,D). The plasma fibrinogen level of the patient was within the normal range $(254 \mathrm{mg} / \mathrm{dL}$; normal range, $180-350 \mathrm{mg} / \mathrm{dL}$ ), and she did not show coagulopathy. Abdominal fat pad biopsy and liver biopsy did not show the presence of amyloid deposits (data not shown). Initially, the patient was diagnosed with primary AL amyloidosis. However, her renal function deteriorated rapidly despite treatment with combined chemotherapies, and she developed ESRD at 18 months after the detection of proteinuria. Eight years after the onset, a definite diagnosis of $\mathrm{A} \alpha$-chain amyloidosis was made by proteomics analysis of glomerular amyloid on renal sample biopsied at 32 years, using laser microdissection (LMD) and liquid chromatography tandem mass spectrometry (LC-MS/MS) [14]. Proteomics analysis detected several tryptic peptides in accordance with the C-terminal region of $A \alpha$-chain (Figure 2). In addition, proteomics analysis detected two tryptic peptides, namely, LSLGAQNLASSQIQR and NPVLITLG, that corresponded to the previously described sequences of the C-terminal region of a fibrinogen variant (position 525-547) induced by a frameshift mutation (4904delG [10]) (Figure 2). Proteomics analysis did not detect a wild-type A $\alpha$-chain sequence after position 523, indicating that amyloid fibrils in our patient were only composed of the variant $A \alpha$-chain fragment. Moreover, proteomics analysis did not detect other tryptic peptides before position 430, suggesting that the $\mathrm{N}$-terminus of the amyloid protein was present around position 430 (Figure 2). To obtain more information on the $\mathrm{N}$-terminus of the amyloid protein, we biochemically investigated the amyloid fibril protein isolated from frozen duodenal mucosa samples by performing methods reported previously [24] and detected several peptides generated by Arg-C peptidase (Figure 2). We also detected a fragment starting with the amino acid residue Thr at position 411, but could not detect peptides before position 410. Therefore, we assumed that Thr411 was the N-terminus and that the amyloid protein was composed of $\mathrm{A} \alpha$-chain fragments with wild-type (positions 411-522) and 
abnormal sequences (position 523-546) (Figure 2). However, we did not detect any wild-type sequence after residue 523 . This result indicated that the wild-type A $\alpha$-chain sequence did not contribute to amyloid formation in our patient, as that observed in another patient with 4897delT [11]. SDS-PAGE showed that the molecular weight of the amyloid fibril protein was approximately $12 \mathrm{kDa}$ (unpublished observation).
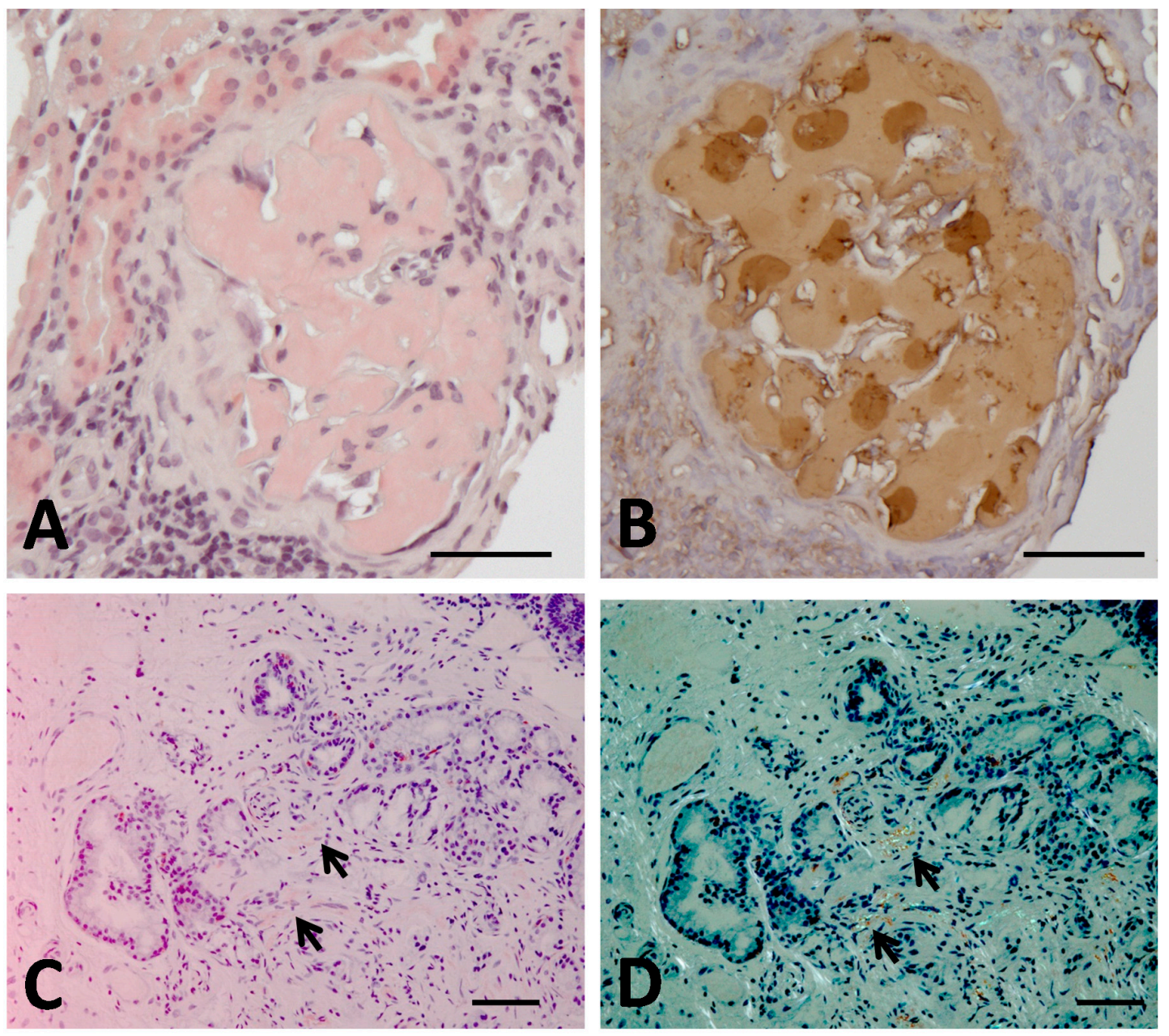

Figure 1. Findings of renal biopsy $(\mathbf{A}, \mathbf{B})$ and duodenal mucosal biopsy $(\mathbf{C}, \mathbf{D})$ in a Japanese A $\alpha$-chain amyloidosis patient [14]. (A,C) Congo red staining. (B) Immunohistochemical staining with anti-human fibrinogen antibody. (D) Congo red staining under polarized light. Renal biopsy at the age of 32 years shows heavy amyloid deposits mainly in glomerulus with almost complete obliteration of the normal glomerular architecture (A). The positive staining is observed in immunohistochemistry (B). Duodenal mucosal biopsy at the age of 40 years demonstrates a small amount of amyloid deposits (arrows, (C)), showing typical apple-green birefringence under polarized light (arrows, (D)). Bars $=50 \mu \mathrm{m}$. 


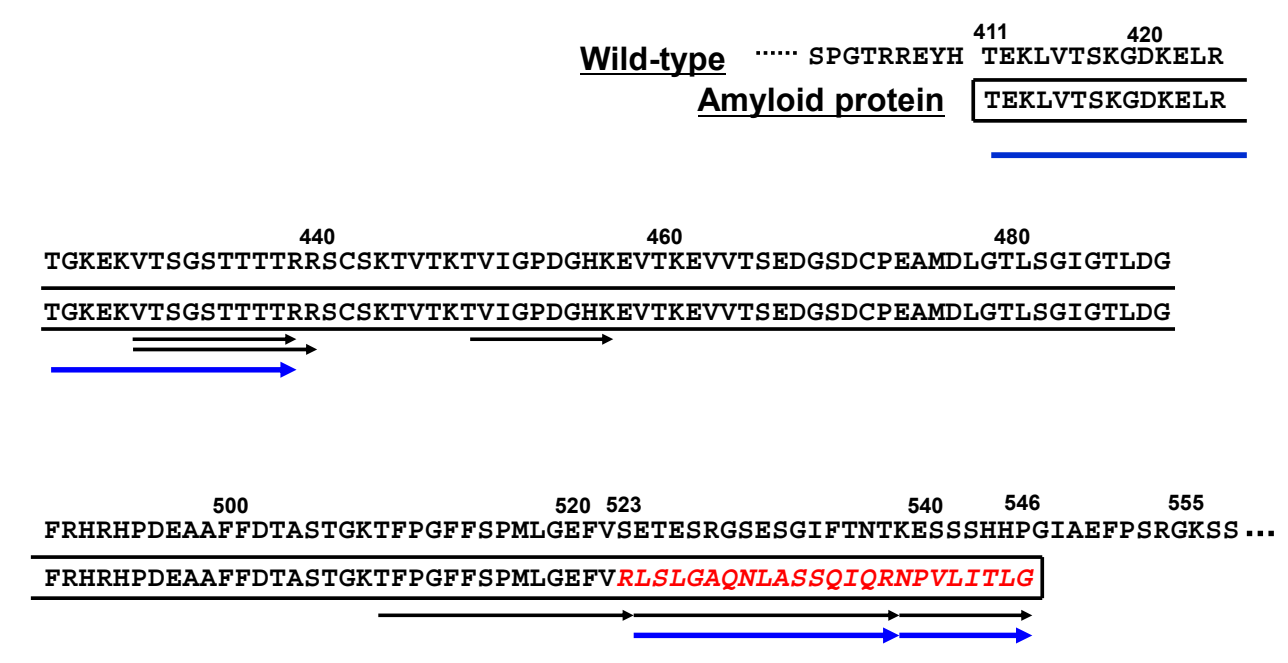

Figure 2. Putative primary structure of amyloid fibril protein in a Japanese $\mathrm{A} \alpha$-chain amyloidosis patient [14]. Amyloid protein in this patient is assumed to be composed of both wild-type sequence (residues 411-522) and an additional fragment (red italic letters) induced by the frameshift variant (residues 523-546). Black arrows denote tryptic peptides detected at laser microdissection (LMD) isolation of glomerular amyloid, and blue arrows denote Arg-C peptides detected at in-gel digestion on SDS-PAGE analysis of duodenal amyloid.

\section{Discussion}

One of the most notable clinical features of A $\alpha$-chain amyloidosis in Asia is that it may still be a quite rare disease, as mentioned above, and only a few Asian patients have been found to date, solely in East Asian countries [12-14,23]. Nephropathy is the main clinical manifestation in Asian patients with $\mathrm{A} \alpha$-chain amyloidosis, which is similar to that observed in patients with $\mathrm{A} \alpha$-chain amyloidosis in other countries. Moreover, Asian and Western patients with A $\alpha$-chain amyloidosis show similar renal pathological findings, including excessive amyloid deposits in the glomeruli $[12,14]$. Genetically, the five Asian patients with $\mathrm{A} \alpha$-chain amyloidosis had five different genetic mutations, of which four were novel (Table 1). E526V, the most common variant in patients with $\mathrm{A} \alpha$-chain amyloidosis in Western countries, was detected in only one Chinese patient with $A \alpha$-chain amyloidosis [23]. The other four mutations detected in the remaining Asian patients with $\mathrm{A} \alpha$-chain amyloidosis have not been reported in patients with $\mathrm{A} \alpha$-chain amyloidosis in other countries to date.

Fibrinogen is a $340-\mathrm{kDa}$ plasma glycoprotein that plays a major role in blood coagulation by converting to fibrin [25,26]. It is composed of two identical subunits, each of which contains an A $\alpha-$, $\mathrm{B} \beta-$, and $\gamma$-chain and is produced by hepatocytes. Mature $\mathrm{A} \alpha$-chain contains 610 amino acids and has a molecular weight of approximately $66 \mathrm{kDa}$ [27]. The detailed pathomechanism underlying amyloid formation from the A $\alpha$-chain remains unclear. Interestingly, all amyloidogenic variants, including the eight frameshift mutations, are present in a specific region of the $\mathrm{A} \alpha$-chain from residues 517 to 555 (Figure 3). These data clearly suggest that the location of FGA mutations is a key factor in amyloid formation. However, because five single amino acid substitutions (Available online: www.geht.org/databaseang/fibrinogen/), such as R554C [28] and R554H [15] at position 517-555, do not induce amyloid formation, it is likely that amyloid formation strongly depends on both the location of the variants and the type of replaced amino acids. In addition, of particular interest in the eight frameshift variants is that the C-terminal sequences resulting from all mutations bear a close resemblance to each other (Figure 3). In fact, C-terminal peptides containing 24 amino acids (SLGAQNL.....VLITLG) are identical among all of the frameshift variants, suggesting that this common sequence may be essential for amyloid formation. A recent study reported the importance of the C-terminal sequence composed of five amino acids (VLITL) in amyloidogenesis [16]. This common sequence may be attributed to the number of deleted nucleotides explained by arithmetical progression 
$(1+3[n-1])$. In addition, it seems to be important that the location of nucleotide deletion should be after TAG within Leu518 (TTA) and Gly519 (GGA), or all nucleotides at position 518 and 519 are deleted, according to the mutation reported by Kang et al. [12]. Indeed, one nucleotide deletion (delC) at position Ala499 (GCC) generated a premature stop codon (TAG) at position 518, and this mutation was non-amyloidogenic [29]. On the other hand, in amyloid proteins associated with frameshift mutations, the length of the wild-type amino acid sequence in the N-terminus seems to vary in each case. In our patient, the presumable start point was Thr411 and the amyloid protein was assumed to contain 136 amino acids (411-546), with a molecular weight of approximately $12 \mathrm{kDa}$ (Figure 2). In contrast, the putative starting point in an amyloid protein associated with 4897delT was assumed to be around Ala499, and its molecular weight was found to be $5 \mathrm{kDa}$ [11]. Therefore, the production of a fragment containing an appropriate length of the wild-type $\mathrm{A} \alpha$-chain sequence and an additional 24 common C-terminal residues seems to be important for amyloid formation. It was assumed that the variant $\mathrm{A} \alpha$-chain containing 546 amino acid residues, which was detected in our patient with a 4-bp deletion [14], was more unstable and could be more easily degraded than the normal $A \alpha$-chain, as reported in other frameshift variants [10]. However, because no amyloid deposits were seen within or outside hepatocytes in our patient, it is possible that the variant $\mathrm{A} \alpha$-chain was secreted by hepatocytes without intracellular aggregation. Therefore, at least in our patient, amyloid formation seemed to be strongly dependent on some proteolytic events after secretion from hepatocytes. In the variant $\mathrm{A} \alpha$-chain with a single amino acid substitution (R554L), the amyloid protein consisted of a fragment containing variant $A \alpha$-chain residues 500-580 [4]. Serpell et al. [30] described the importance of residues 500-521 in amyloidogenesity because this portion was also present in a frameshift variant (4897delT) [11]. This portion was also detected in our patient (Figure 2). This suggests that an amyloidogenic fragment of an appropriate length for fibril formation generated from a variant $\mathrm{A} \alpha$-chain through an aberrant proteolytic event is important for amyloid formation. However, mechanisms underlying the generation of amyloidogenic fragments or their escape from further processing are unclear, and further in vivo or in vitro investigations should be performed to address these questions.

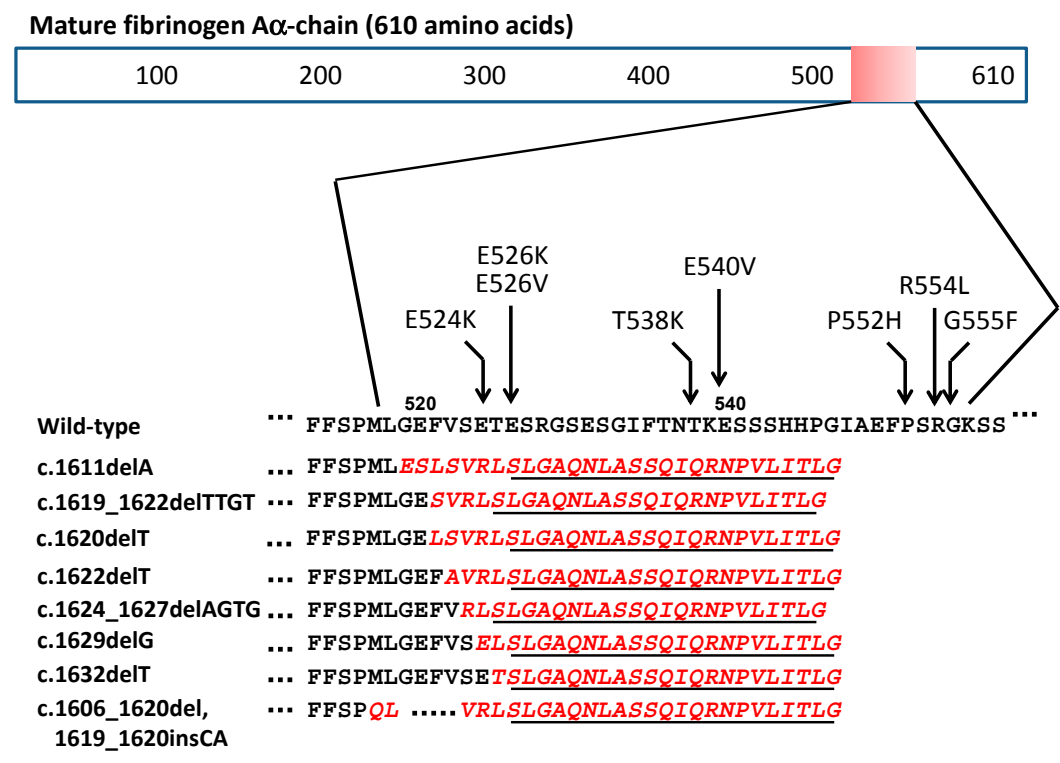

Figure 3. The location of 16 amyloidogenic FGA variants. All amyloidogenic variants crowd in a quite limited portion from residue 517 to 555 of the mature A $\alpha$-chain. In eight frameshift variants, the C-terminal sequences resulted from frameshift variants (red italic letters) bear a close resemblance to each other, and the C-terminal peptides consisting of 24 amino acids (underline) are identical. 
Thus, more patients with $\mathrm{A} \alpha$-chain amyloidosis may be present in Asia. However, the majority of these patients may have been misdiagnosed with other types of systemic amyloidosis. Asian and European patients with $\mathrm{A} \alpha$-chain amyloidosis do not show remarkable differences with respect to clinical manifestations; however, the most prevalent genetic variant E526V in European patients may not be common in Asian patients. Recently, several effective therapies have been established for treating different types of systemic amyloidosis; however, the therapeutic strategy for treating each type of amyloidosis is different [13,17,31-42] (Table 2), highlighting the importance of the correct diagnosis of the disease at an early stage. Moreover, the possibility of A $\alpha$-chain amyloidosis should always be considered in sporadic cases of amyloid nephropathy, even in Asian countries. In our patient, proteomic analysis by performing LMD and LC-MS/MS not only helped in making the correct diagnosis, but also helped in obtaining information on the whole sequence of the amyloid fibril protein by using small sections of an old formalin-fixed, paraffin-embedded tissue sample obtained from the patient [14].

Table 2. Therapeutic options in major systemic amyloidoses.

\begin{tabular}{lllc}
\hline \multicolumn{1}{c}{ Types of Systemic Amyloidosis } & \multicolumn{1}{c}{ Precursor Proteins } & \multicolumn{1}{c}{ Therapeutic Options } \\
\hline Hereditary ATTR amyloidosis & Transthyretin & References \\
Primary AL amyloidosis & Immunoglobulin light chain & Chemotherapies, stem cell transplantation & [31-35] \\
Reactive AA amyloidosis & Serum amyloid A (SAA) & Control of underlying diseases, biologic agents \\
Fibrinogen A $\alpha$-chain amyloidosis & Fibrinogen A $\alpha$-chain & Renal transplant, liver and renal transplant & [36-38] \\
Apolipoprotein A-I amyloidosis & Apolipoprotein A-I & Renal transplant, liver and renal transplant & [13,17] \\
Apolipoprotein A-II amyloidosis & Apolipoprotein A-II & Renal transplant & [41] \\
\hline
\end{tabular}

\section{Conclusions}

Clinical pictures in Asian A $\alpha$-chain amyloidosis patients are almost similar to those in Western counties. While the features of genotype in FGA may be different between Asian and European patients, it is common that all amyloidogenic variants are located in the C-terminal region (amino acid residues 517-555) of mature A $\alpha$-chain. The precise number of Asian patients with A $\alpha$-chain amyloidosis is unclear. However, patients with $\mathrm{A} \alpha$-chain amyloidosis do exist in Asian countries, and the majority of these patients may be diagnosed with other types of systemic amyloidosis.

Acknowledgments: This study was supported by a Grant-in-Aid for Scientific Research in Japan (Kaken, 16K21066 to Tsuneaki Yoshinaga) and a grant from the Hokuto Foundation for Bioscience (Masahide Yazaki and Tsuneaki Yoshinaga).

Conflicts of Interest: The authors declare no conflict of interest.

\section{Abbreviations}

A $\alpha$-chain amyloidosis

ESRD

LMD

LC-MS/MS
Fibrinogen $\mathrm{A} \alpha$-chain amyloidosis

End-stage renal disease

Laser microdissection

Liquid chromatography-tandem mass spectrometry

\section{References}

1. Ostertag, B. Familiere amyloid-erkrankung. Z. Menschl. Vererbungs Konstit. Pehre 1950, 30, 105-115.

2. Benson, M.D. Ostertag revisited: The inherited systemic amyloidosis without neuropathy. Amyloid 2005, 12, 75-87. [CrossRef] [PubMed]

3. Nichols, W.C.; Dwulet, F.E.; Liepnieks, J.; Benson, M.D. Variant apolipoprotein AI as a major constituent of a hemian hereditary amyloid. Biochem. Biophys. Res. Commun. 1988, 156, 762-768. [CrossRef]

4. Benson, M.D.; Liepnieks, J.; Uemichi, T.; Wheeler, G.; Correa, R. Hereditary renal amyloidosis associated with a mutant fibrinogen $\alpha$-chain. Nat. Genet. 1993, 3, 252-255. [CrossRef] [PubMed] 
5. Pepys, M.B.; Hawkins, P.N.; Booth, D.R.; Vigushin, D.M.; Tennent, G.A.; Soutar, A.K.; Totty, N.; Nguyen, O.; Blake, C.C.; Terry, C.J.; et al. Human lysozyme gene mutations cause hereditary systemic amyloidosis. Nature 1993, 362, 553-557. [CrossRef] [PubMed]

6. Benson, M.D.; Liepnieks, J.; Yazaki, M.; Yamashita, T.; Hamidi Asl, K.; Guenther, B.; Kluve-Beckerman, B. A new human hereditary amyloidosis: The result of a stop-codo mutation in the apolipoprotein AII gene. Genomics 2001, 72, 272-277. [CrossRef] [PubMed]

7. Nasr, S.H.; Dasari, S.; Hasadsri, L.; Theis, J.D.; Vrana, J.A.; Gertz, M.A.; Muppa, P.; Zimmermann, M.T.; Grogg, K.L.; Dispenzieri, A.; et al. Novel type of renal amyloidosis derived from apolipoprotein C-II. J. Am. Soc. Nephrol. 2017, 28, 439-445. [CrossRef] [PubMed]

8. Valleix, S.; Verona, G.; Jourde-Chiche, N.; Nédelec, B.; Mangione, P.P.; Bridoux, F.; Mangé, A.; Dogan, A.; Goujon, J.M.; Lhomme, M.; et al. D25V apolipoprotein C-III variant causes dominant hereditary systemic amyloidosis and confers cardiovascular protective lipoprotein profile. Nat. Commun. 2016, 7, 10353. [CrossRef] [PubMed]

9. Uemichi, T.; Liepnieks, J.J.; Benson, M.D. Hereditary renal amyloidosis with a novel variant fibrinogen. J. Clin. Investig. 1994, 93, 731-736. [CrossRef] [PubMed]

10. Uemichi, T.; Liepnieks, J.J.; Yamada, T.; Gertz, M.A.; Bang, N.; Benosn, M.D. A frame shift mutation in the Fibrinogen A $\alpha$-chain gene in a kindred with renal amyloidosis. Blood 1996, 87, 4197-4203. [PubMed]

11. Hamidi Asl, L.; Liepnieks, J.J.; Uemichi, T.; Rebibou, J.M.; Justrabo, E.; Droz, D.; Mousson, C.; Chalopin, J.M.; Benson, M.D.; Delpech, M.; et al. Renal amyloidosis with a frame shift mutation in Fibrinogen A $\alpha$-chain gene producing a novel amyloid protein. Blood 1997, 90, 4799-4805. [PubMed]

12. Kang, H.G.; Bybee, A.; Ha, I.S.; Park, M.S.; Gilbertoson, J.A.; Cheong, H.I.; Choi, Y.; Hawkins, P.N. Hereditary amyloidosis in early childhood associated with a novel insertion-deletion (indel) in the fibrinogen A $\alpha$ chain gene. Kidney Int. 2005, 68, 1994-1996. [CrossRef] [PubMed]

13. Gillmore, J.D.; Lachmann, H.J.; Rowczenio, D.; Gilbertoson, J.A.; Zeng, C.H.; Liu, Z.H.; Li, L.S.; Wechalekar, A.; Hawkins, P.N. Diagnosis, pathogenesis, treatment, and prognosis of hereditary fibrinogen A $\alpha$-chain amyloidosis. J. Am. Soc. Nephrol. 2009, 20, 444-451. [CrossRef] [PubMed]

14. Yazaki, M.; Yoshinaga, T.; Sekijima, Y.; Nishio, S.; Kanizawa, Y.; Kametani, F.; Miyashita, K.; Hachiya, N.; Higuchi, K.; Ikeda, S. The first pure form of Ostertag-type amyloidosis in Japan: A sporadic case of hereditary fibrinogen A $\alpha$-chain amyloidosis associated with a novel frameshift variant. Amyloid 2015, 22, 142-144. [CrossRef] [PubMed]

15. Rowczenio, D.; Stensland, M.; de Souza, G.A.; Strøm, E.H.; Gilbertson, J.A.; Taylor, G.; Rendell, N.; Minogue, S.; Efebera, Y.A.; Lachmann, H.J.; et al. Renal amyloidosis associated with 5 novel variants in the fibrinogen A alpha cahin protein. Kidney Int. Rep. 2017, 2, 461-469. [CrossRef] [PubMed]

16. Garnier, C.; Briki, F.; Nedelec, B.; Le Pogamp, P.; Dogan, A.; Rioux-Leclercq, N.; Goude, R.; Beugnet, C.; Martin, L.; Delpech, M.; et al. VLITL is a major cross-b-sheet signal for fibrinogen A $\alpha$-chain frameshift variants. Blood 2017, 130, 2799-2807. [CrossRef] [PubMed]

17. Stangou, A.J.; Banner, N.R.; Hendry, B.M.; Rela, M.; Portmann, B.; Wendon, J.; Monaghan, M.; MacCarthy, P.; Buxton-Thomas, M.; Mathias, C.; et al. Hereditary fibrinogen A $\alpha$-chain amyloidosis: Phenotypic characterization of a systemic disease and the role of liver transplantation. Blood 2010, 115, 2998-3007. [CrossRef] [PubMed]

18. Mourad, G.; Delabre, J.P.; Garigue, V. Cardiac amyloidosis with the E526V mutation of the fibrinogen A $\alpha$-chain. N. Engl. J. Med. 2008, 358, 2847-2848. [CrossRef] [PubMed]

19. Lachmann, H.J.; Booth, D.R.; Booth, S.E.; Bybee, A.; Gilbertson, J.A.; Gillmore, J.D.; Pepys, M.K.; Hawkins, P.N. Misdiagnosis of hereditary amyloidosis as AL (primary) amyloidosis. N. Engl. J. Med. 2002, 346, 1786-1791. [CrossRef] [PubMed]

20. Machado, J.R.; da Silva, M.V.; de Menezes Neves, P.D.M.; de Oliveira, F.A.; Corrêa, R.R.M.; Rodrigues, W.V.D.; Benson, M.D.; dos Reis, M.A. Fibrinogen A $\alpha$-chain amyloidosis: Report of the first case in Latin America. Amyloid 2013, 20, 52-55. [CrossRef] [PubMed]

21. Tavares, I.; Oliveira, J.P.; Pinho, A.; Moreira, L.; Rocha, L.; Santos, J.; Pinheiro, J.; Costa, P.P.; Lobato, L. Unrecognized fibrinogen A $\alpha$-chain amyloidosis: Results from targeted genetic testing. Am. J. Kidney Dis. 2017, 70, 235-243. [CrossRef] [PubMed] 
22. Tavares, I.; Lobato, L.; Matos, C.; Santos, J.; Moreira, P.; Saraiva, M.J.; Henriques, A.C. Homozygosity for the E526V mutation in fibrinogen A alpha-chain amyloidosis: The first report. Case Rep. Nephrol. 2015. [CrossRef] [PubMed]

23. Yao, Y.; Wang, S.X.; Zhang, Y.K. Hereditary fibrinogen A $\alpha$-chain amyloidosis caused by the E526V mutation: A case report and literature review. Beijing Da Xue Xue Bao Yi Xue Ban 2014, 46, 802-804. (In Chinese) [PubMed]

24. Yazaki, M.; Fushimi, T.; Tokuda, T.; Kametani, F.; Yamamoto, K.; Matsuda, M.; Shimojo, H.; Hoshii, Y.; Higuchi, K.; Ikeda, S. A patient with severe renal amyloidosis associated with an immunoglobulin $\gamma$-heavy chain fragment. Am. J. Kidney Dis. 2004, 43, E23-E28. [CrossRef] [PubMed]

25. Weisel, J.W. Fibrinogen and fibrin. Adv. Protein Chem. 2005, 70, 247-299. [PubMed]

26. Weisel, J.W.; Litvinov, R.I. Mechanism of fibrin polymerization and clinical implications. Blood 2013, 121, 1712-1719. [CrossRef] [PubMed]

27. Kant, J.A.; Fornace, A.J., Jr.; Saxe, D.; Simon, M.I.; McBride, O.W.; Crabtree, G.R. Evolution and organization of the fibrinogen locus on chromosome 4: Gene duplication accompanied by transposition and inversion. Proc. Natl. Acad. Sci. USA 1985, 82, 2344-2348. [CrossRef] [PubMed]

28. Koopman, J.; Haverkate, F.; Grimbergen, J.; Lord, S.T.; Mosesson, M.W.; DiOrio, J.P.; Siebenlist, K.R.; Legrand, C.; Soria, J.; Soria, C.; et al. The molecular basis for fibrinogen Dusart (Aa554 Arg->Cys) and its association with abnormal fibrinogen polymerization and thrombophilia. J. Clin. Investig. 1993, 91, 1637-1643. [CrossRef] [PubMed]

29. Margaglione, M.; Vecchione, G.; Santacroce, R.; D’Angelo, F.; Casetta, B.; Papa, M.L.; Grandone, E.; Di Minno, G. A frameshift mutation in the human fibrinogen $\alpha$-chain gene ( $\alpha$ (499) Ala frameshift stop) leading to dysfibrinogen San Giovanni Rotondo. Thromb. Haemost. 2001, 86, 1483-1488. [PubMed]

30. Serpell, L.C.; Benson, M.D.; Liepnieks, J.J.; Fraser, P.E. Structural analyses of fibrinogen amyloid fibrils. Amyloid 2007, 14, 199-203. [CrossRef] [PubMed]

31. Ericzon, B.G.; Wilczek, H.E.; Larsson, M.; Wijayatunga, P.; Stangou, A.; Pena, J.R.; Furtado, E.; Barroso, E.; Daniel, J.; Samuel, D.; et al. Liver Transplantation for Hereditary Transthyretin Amyloidosis: After 20 Years Still the Best Therapeutic Alternative? Transplantation 2015, 99, 1847-1854. [CrossRef] [PubMed]

32. Coelho, T.; Maia, L.F.; da Silva, A.M.; Cruz, M.W.; Planté-Bordeneuve, V.; Suhr, O.B.; Conceiçao, I.; Schmidt, H.H.; Trigo, P.; Kelly, J.W.; et al. Long-term effects of tafamidis for the treatment of transthyretin familial amyloid polyneuropathy. J. Neurol. 2013, 260, 2802-2814. [CrossRef] [PubMed]

33. Berk, J.L.; Suhr, O.B.; Obici, L.; Sekijima, Y.; Zeldenrust, S.R.; Yamashita, T.; Heneghan, M.A.; Gorevic, P.D.; Litchy, W.J.; Wiesman, J.F.; et al. Repurposing Diflunisal for Familial Amyloid Polyneuropathy: A Randomized Clinical Trial. JAMA 2013, 310, 2658-2667. [CrossRef] [PubMed]

34. Coelho, T.; Adams, D.; Silva, A.; Lozeron, P.; Hawkins, P.N.; Mant, T.; Perez, J.; Chiesa, J.; Warrington, S.; Tranter, E.; et al. Safety and efficacy of RNAi therapy for transthyretin amyloidosis. N. Engl. J. Med. 2013, 369, 819-829. [CrossRef] [PubMed]

35. Benson, M.D.; Kluve-Beckerman, B.; Zerdenrust, S.R.; Siesky, A.M.; Bodenmiller, D.M.; Showalter, A.D.; Sloop, K.W. Targeted suppression of an amyloidogenic transthyretin with antisense oligonucleotides. Muscle Nerve 2006, 33, 609-618. [CrossRef] [PubMed]

36. Katoh, N.; Matsuda, M.; Tsuchiya-Suzuki, A.; Ikeda, S. Regression of gastroduodenal amyloid deposition in systemic AL amyloidosis after intensive chemotherapies. Br. J. Haematol. 2011, 153, 535-538. [CrossRef] [PubMed]

37. Katoh, N.; Matsushima, A.; Kurozumi, M.; Matsuda, M.; Ikeda, S. Marked and rapid regression of hepatic amyloid deposition in a patient with systemic light chain (AL) amyloidosis after high-dose melphalan therapy with stem cell transplantation. Intern. Med. 2014, 53, 1991-1995. [CrossRef] [PubMed]

38. Landau, H.; Hassoun, H.; Rosenzweig, M.A.; Maurer, M.; Liu, J.; Flombaum, C.; Bello, C.; Hoover, E.; Riedel, E.; Giralt, S.; et al. Bortezomib and dexamethasone consolidation following risk-adapted melphalan and stem cell transplantation for patients with newly diagnosed light-chain amyloidosis. Leukemia 2013, 27, 823-828. [CrossRef] [PubMed]

39. Okuda, Y.; Takasugi, K. Successful use of a humanized anti-interleukin-6 receptor antibody, tocilizumab, to treat amyloid a amyloidosis complicating juvenileidiopathic arthritis. Arthritis Rheum. 2006, 54, 2997-3000. [CrossRef] [PubMed] 
40. Okuda, Y.; Ohnishi, M.; Matoba, K.; Jouyama, K.; Yamada, A.; Sawada, N.; Mokuda, S.; Murata, Y.; Takasugi, K. Comparison of the clinical utility of tocilizumab and anti-TNF therapy in AA amyloidosis complicating rheumatic diseases. Mod. Rheumatol. 2014, 24, 137-143. [CrossRef] [PubMed]

41. Gillmore, J.D.; Stangou, A.J.; Lachmann, H.J.; Goodman, H.J.; Wechalekar, A.D.; Acheson, J.; Tennent, G.A.; Bybee, A.; Gilbertson, J.; Rowczenio, D.; et al. Organ transplantation in hereditary apolipoprotein AI amyloidosis. Am. J. Transplant. 2006, 6, 2342-2347. [CrossRef] [PubMed]

42. Magy, N.; Liepnieks, J.J.; Yazaki, M.; Kluve-Beckerman, B.; Benson, M.D. Renal transplantation for apolipoprotein AII amyloidosis. Amyloid 2003, 10, 224-228. [CrossRef] [PubMed]

(C) 2018 by the authors. Licensee MDPI, Basel, Switzerland. This article is an open access article distributed under the terms and conditions of the Creative Commons Attribution (CC BY) license (http://creativecommons.org/licenses/by/4.0/). 